\title{
Spatial heterogeneity increases diversity and stability in grassland bird communities
}

\author{
Torre J. Hovick, ${ }^{1,3}$ R. Dwayne Elmore, ${ }^{1}$ Samuel D. Fuhlendorf, ${ }^{1}$ David M. Engle, ${ }^{1}$ and Robert G. Hamilton ${ }^{2}$ \\ ${ }^{1}$ Department of Natural Resource Ecology and Management, Oklahoma State University, Stillwater, Oklahoma 74074 USA \\ ${ }^{2}$ Tallgrass Prairie Preserve, The Nature Conservancy, Box 458, Pawhuska, Oklahoma 74056 USA
}

\begin{abstract}
Grasslands are inherently dynamic in space and time, evolving with frequent disturbance from fire and herbivores. As a consequence of human actions, many remaining grasslands have become homogenous, which has led to reduced ecosystem function, biodiversity loss, and decreased ecological services. Previous research has shown that restoring inherent heterogeneity to grasslands can increase avian diversity, but the amount of heterogeneity (i.e., number of patches or fire return interval) and the impact on avian community stability have yet to be investigated. We used a unique landscape-level design to examine avian response to interacting fire and grazing across multiple experimental landscapes that represented a gradient of fire- and grazing-dependent heterogeneity. We used seven landscapes (430-980 ha; $\bar{x}=627$ ha) with varying levels of patchiness ranging from annually burned (one single patch) with spring-only fires to a four-year fire return interval with spring and summer fires (eight patches). This design created a range of heterogeneity as a result of pyric herbivory, an ecological process in which fire and grazing are allowed to interact in space and time. We found that greater heterogeneity across experimental landscapes resulted in increased avian diversity and stability over time. An index of bird community change, quantified as the sum of the range of detrended correspondence analysis axis site scores, was nearly four times greater in the most homogenous experimental landscape when compared to the most heterogeneous experimental landscape. Species responses were consistently positively associated with increased heterogeneity at the landscape scale, and within-experimentallandscape responses were most often related to litter cover, litter accumulation, and vegetation height. We conclude that increased fire- and grazing-dependent heterogeneity can result in high variability in the bird community at finer, transect scales, but increased diversity and stability at broad landscape scales. We recommend that future management efforts in rangelands focus on restored disturbance processes to increase heterogeneity and improve grassland bird conservation.
\end{abstract}

Key words: Ammodramus henslowii; conservation; disturbance; diversity-stability relationships; fire; grassland birds; grazing pressure; Henslow's Sparrow; Oklahoma; pyric herbivory; spatial scale; tallgrass prairie.

\section{INTRODUCTION}

The promotion of uniform and moderate grazing across rangelands has become a central paradigm for grassland management and, although it has undoubtedly limited severe grazing on rangelands, it has greatly diminished the natural complexity of this biome (Fuhlendorf and Engle 2001). This simplification, or homogenization, of rangeland landscapes has resulted in a decline of ecosystem structure and function, ecosystem services, and overall biodiversity (Anderson 2006, Derner et al. 2009, Fuhlendorf et al. 2009). Recognition of the state of rangelands and an understanding of the importance of ecosystem complexity and heterogeneity has presented a challenge to ecologists and managers alike because it suggests the need for an alternative

Manuscript received 4 June 2014; revised 8 September 2014; accepted 23 September 2014. Corresponding Editor: R. L. Knight.

${ }^{3}$ E-mail: torre.hovick@gmail.com paradigm for ecosystem management (Fuhlendorf et al. 2012). Because heterogeneity is the root of diversity (Wiens 1997, Fahrig et al. 2011), a model for managing rangelands that promotes the restoration of variability that is inherent to this system may diversify structure and increase ecosystem function (Fuhlendorf et al. 2012). Furthermore, while it is generally accepted that heterogeneity increases diversity (Benton et al. 2003, Fahrig et al. 2011), there is a need to understand the level of heterogeneity that maximizes conservation in an applied framework if research is expected to have an effect on management.

Fire and grazing are key forces in the maintenance of grass-dominated systems, and their frequency, intensity, and effects have been variable in time and space at multiple scales (Steinauer and Collins 1996, Hoekstra et al. 2005). Recently, a model for managing rangelands that restores the interactive effects of fire and grazing through an ecological process known as pyric herbivory has been shown to restore grassland heterogeneity and 
increase diversity across multiple trophic levels (Fuhlendorf and Engle 2004, Fuhlendorf et al. 2009). Heterogeneity in this context is derived from variability in vegetation structure, composition, density, and biomass, which are highly dependent on fire and grazing processes and the interaction of these processes (Fuhlendorf and Engle 2001, 2004, Allred et al. 2011, McGranahan et al. 2012). Through pyric herbivory, heterogeneity results from a shifting grassland mosaic at broad scales as herbivores and fire interact through a series of positive and negative feedbacks (Fuhlendorf et al. 2009, McGranahan et al. 2012, Augustine and Derner 2013). As a result, diversity has increased across multiple trophic levels (Fuhlendorf et al. 2006, 2010, Engle et al. 2008, Hovick et al. 2014), but how this affects community stability and variability over time is mostly still unknown.

Few studies have addressed the direct influence of spatial heterogeneity on community temporal variability or how disturbance history alters the spatial scale of community stability over time (Wu and Loucks 1995, Foster et al. 2003). However, it is well supported that biological diversity contributes to ecosystem stability (Tilman 1996, Tartowski et al. 1997, Jiang and Pu 2009, Downing et al. 2014), and that biodiversity is a driver of many ecological processes and not simply a product of them (Naeem 2002). In most cases, however, the effects of diversity on stability have been investigated at lower trophic levels or highly controlled experiments and few studies have examined the effects of restored grassland heterogeneity on the stability of upper trophic levels such as the native bird community. In this circumstance, we define stability as a reduction in the temporal variability of an attribute within an ecosystem (Downing et al. 2014). Specifically, we will focus on population attributes associated with diversity of the grassland bird community (i.e., the temporal variability in species abundance and diversity).

There needs to be a better understanding of how the timing and scale of restored natural disturbance processes influence diversity and stability (Christensen 1997, Wiens 1997). It has been shown that high habitat heterogeneity can promote temporal stability through several mechanisms, including stabilization of resources and increased refugia from minor disturbance or predation (Brown 2007), but this probably depends on scale. Despite many conservation and restoration programs focused on generating and maintaining heterogeneity to promote biodiversity and system stability (Palmer et al. 1997, Benton et al. 2003, Carey 2003), there is limited empirical evidence supporting the impacts of restored heterogeneity at broad scales relevant to management or on terrestrial fauna. The implications of such research would be applicable to ecological theory and management practices simultaneously (Micheli et al. 1999). Furthermore, a better understanding of the impacts of restored heterogeneity on community stability will improve conservation efforts because variation in community processes can decrease reliability of ecosystem processes (Naeem and Li 1997), reduce ecosystem services (Cardinale et al. 2012), and increase extinction risk (Pimm et al. 1995).

To improve our understanding of the impacts of restored heterogeneity on avian diversity, stability, and individual species abundances, we investigated avian response to a gradient of fire- and grazing-dependent heterogeneity that resulted from pyric herbivory. We used a unique landscape-level design across seven experimental landscapes that varied from annually burned (i.e., one patch) to a four-year fire return interval with spring and late-summer prescribed fires (i.e., eight patches). We hypothesized that greater landscape-level heterogeneity would increase avian diversity and result in greater community stability over time, and that individual species abundances would vary greatly across the gradient of heterogeneity as a result of specific life history traits.

\section{Methods \\ Study site}

Our study took place on The Nature Conservancy's Tallgrass Prairie Preserve (TGPP) in northeast Oklahoma, USA from 2011 to 2013. This area comprises the southern extent of the Flint Hills region of the Great Plains and is part of the largest remaining tallgrass prairie in North America. The TGPP is a 16000-ha area dominated by tallgrass prairie plant community. Dominant grasses include Andropogon gerardii Vitman, Schizachyrium scoparium Nash, Panicum virgatum L., and Sorghastrum nutans (L.) Nash. Dominant forbs at the preserve include ironweed (Veronia spp.), milkweed (Asclepias spp.), and ashy sunflower (Helianthus mollis). The climate is temperate with hot summers (average high of $31.4^{\circ} \mathrm{C}$ for June $2011-2013$ ) and cold winters (average low of $-4.81^{\circ} \mathrm{C}$ for January 2011-2013). Precipitation during the growing season (April-October) was $478 \mathrm{~mm}, 624 \mathrm{~mm}$, and $875 \mathrm{~mm}$ for 2011, 2012, and 2013, respectively.

\section{Experimental design}

Our unique landscape-level design consisted of seven large-scale experimental landscapes that varied in size from 430 to 980 ha $(\bar{x}=627 \mathrm{ha})$ and ranged from one patch (i.e., the entire experimental landscape) to eight patches (Fig. 1). Burn patch size varied depending on the number of patches within the landscape, but averaged 170 ha for the six landscapes with fire return intervals $>1$ year. Experimental landscapes had no interior fences and were enclosed by a single exterior fence for organizational purposes. The attraction and preference of grazing animals to recently burned areas creates structural heterogeneity because animals graze recently burned portions of the landscape while reducing their use of areas that have gone unburned in multiple years. This behavior results in a range of vegetation structure, with recently burned and grazed patches having shorter 


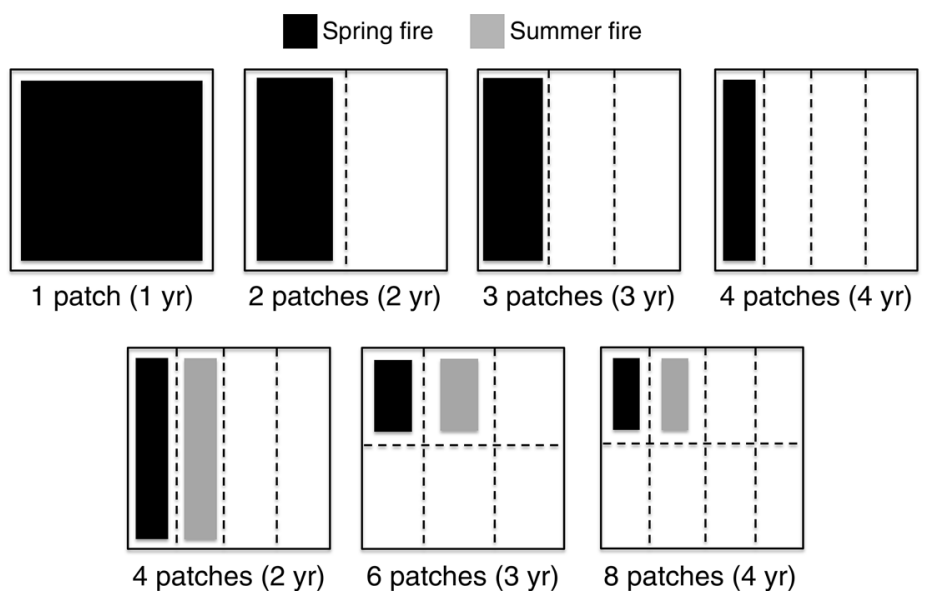

FIG. 1. Experimental design at The Nature Conservancy's Tallgrass Prairie Preserve, Oklahoma, USA, used to examine the influence of a gradient of fire and grazing heterogeneity on the grassland breeding bird community. Each box represents an exterior fence of an experimental landscape and below it we have included the number of patches within each landscape and the fire return interval (parenthetically). Dashed lines are hypothetical patch divisions created by discrete fire and focal grazing; no experimental landscape had interior fencing. The dark boxes represent spring fires (March-April) and the gray boxes represent summer fires (late July-August). Experimental landscapes ranged from 430 to 980 ha ( $\bar{x}=627$ ha) and patch sizes ranged from 79 to 378 ha $(\bar{x}=170$ ha) in landscapes managed for heterogeneity.

vegetation devoid of litter, while unburned areas have taller vegetation and greater amounts of litter (Allred et al. 2011, McGranahan et al. 2012). Therefore, we created spatial heterogeneity within seven experimental landscapes by manipulating the number and relative size of burn patches. As patch number increases and the relative size of a patch decreases (range 79-378 ha), grazing animals will concentrate more heavily on such a patch, increasing the level of heterogeneity within an experimental landscape (Allred et al. 2011). Each experimental landscape was assigned a fire return interval (i.e., 1, 2, 3, or 4 years) and a season of fire (i.e., spring only or spring and summer). Experimental landscapes with one to four patches were burned in the spring (March to April); landscapes with four to eight patches were burned in the spring and summer (July to August). Application of fires began in 2008 and continued through 2013, and only one patch was burned per experimental landscape, season, and year. All experimental landscapes were in similar condition, with similar potential productivity, and were moderately grazed by domestic cattle (Bos taurus) at 2.4 AUM/ha (AUM is animal unit months, a standard metric of stocking rate). Spring and summer burns were done following prescriptions set by TGPP personnel and only Nature Conservancy employees were allowed to burn. Fuel loads and fire behavior varied dependent upon fire return interval of the experimental landscape and the weather conditions, with summer fires generally resulting in patchier burns as a consequence of higher fuel moisture and conducted under higher relative humidity than spring fires.

\section{Data collection}

We used line transect surveys to record the grassland bird community. Line transects are preferred to point counts in open habitats due to higher sampling efficiency, and cryptic species are more likely to be observed (Buckland 2001). We randomly placed 12 transects, $200 \mathrm{~m}$ long, in each of the seven experimental landscapes (i.e., 84 transects total) because we were primarily interested in landscape-level (to correspond to the heterogeneity gradient) responses to heterogeneity and therefore wanted equal sampling effort across experimental landscapes. Transects were placed $>100$ $\mathrm{m}$ from experimental landscape borders and $>200 \mathrm{~m}$ from other transects. We conducted surveys from sunrise until 10:30 hours (Central Standard Time), when grassland birds are most active (Ralph et al. 1993), and on days with no precipitation and wind speeds less than $15 \mathrm{~km} / \mathrm{h}$. On each transect, observers recorded every bird seen and heard within $50 \mathrm{~m}$ of the line as they walked at a slow pace (i.e., $\sim 1 \mathrm{~m} / \mathrm{s}$ ). We limited observation to $50 \mathrm{~m}$ to maximize detectability and decrease potential observer error when identifying cryptic grassland species at long distances (Pillsbury et al. 2011). Additionally, observers recorded the species and perpendicular distance from the line for each encounter. We conducted surveys four times annually ( every 10 days) from 15 May through 10 July.

We measured plant community characteristics once each breeding season in mid June to correspond with avian surveys. We recorded vegetation at the midpoint of each transect and placed a $0.5-\mathrm{m}^{2}$ quadrat on the transect and sampled every $2.5 \mathrm{~m}$ in each cardinal direction for a distance of $10 \mathrm{~m}(n=17$ total quadrats/ plot). We estimated canopy cover for the following plant functional groups: graminoid, forb, litter, bare ground, and shrub. Additionally, we measured vegetation height and litter depth in each quadrat using standardized methods. Finally, we measured vegetation density using 
a Nudd's board adapted for grassland/shrubland use by observing the percentage of obstruction on a Nudd's profile board from a distance of $7.5 \mathrm{~m}$ away and an observer height of $1 \mathrm{~m}$ above ground level (Nudds 1977, Guthery et al. 1981). We recorded vegetation densities in each cardinal direction at every plot.

\section{Data analysis}

We assessed the effects of heterogeneity on avian diversity by calculating Shannon diversity $(H)$ at the experimental landscape level (Pillsbury et al. 2011). This diversity measure simultaneously takes into account the number of bird species present in an experimental landscape and the relative abundances of individual bird species. We overcame a potential drawback of diversity indices associated with obscured species identities by restricting our analysis to five grassland breeding birds that made up the majority of our detections. Then, to explicitly examine the influence of heterogeneity on diversity, we ran a general linear model with the number of patches within an experimental landscape as our dependent variable and used the calculated diversity scores $(H)$ as our response variable. This approach allowed for simple interpretation of the effects of heterogeneity on grassland bird diversity.

We examined bird community composition and stability over time by subjecting grassland bird abundance data for each experimental landscape to indirect gradient analysis using detrended correspondence analysis, DCA. DCA has been used to summarize general similarities and differences among grassland bird communities and can elucidate compositional dynamics over time (Collins 2000, Fuhlendorf et al. 2006). This method of analysis uses detrending and rescaling to deal with the arch effect and compression near the ends of gradients that can flaw reciprocal averaging and other correspondence analysis. Additionally, DCA presents sample and site scores expressed in standard deviation units, which makes interpreting results easier and more intuitive than some other forms of ordination. All analyses were conducted in Canoco 5.0 using default settings for DCA unconstrained ordination (ter Braak and Šmilauer 2012); software is available online. ${ }^{4}$ After completing the DCA, we then used loading scores for site samples (i.e., each experimental landscape and year combination) to project differences in avian community change over time. We call this metric the community change index because it refers to the change in the bird community at the experimental landscape scale across the three years of the study. Differences in community composition are measured by standard deviation units, and therefore, experimental landscapes with a greater range of axis scores have the most change in the bird community, whereas those experimental landscapes with a smaller range in axis scores represent the most stable

\footnotetext{
${ }^{4}$ http://www.microcomputerpower.com/
}

bird communities over time. In addition to projecting site scores to show relationships of dissimilarity in ordination space, we used the community change index as a response variable in a general linear model to show the relationship between bird community stability and fire- and grazing-dependent heterogeneity.

In addition to among-experimental-landscape dynamics, we used DCA to investigate finer-scale patterns of community composition within landscapes at the transect level. For this analysis, we performed an indirect gradient analysis using DCA on transect-level bird abundances. We then used the individual DCA axis 1 site scores to calculate an average of all transects (i.e., 12 per experimental landscape) within an experimental landscape for each year of the study. Next, we calculated a standard deviation for the average site scores within each year. We then took an average of the standard deviation for each experimental landscape over the three years of the study and calculated a standard error of the averaged standard deviation. We call this metric the variation index because it refers to variation in the bird community at fine scales over time. Finally, we used a general linear model to quantify the effect of fire- and grazing-dependent heterogeneity (i.e., the number of patches/experimental landscape) on transect-level variation in the bird community (i.e., variation index). Increased standard deviation in this analysis would indicate greater variability in the avian community at the transect scale over time, a result that would be expected at finer scales within heterogeneous environments.

We addressed individual species' responses to fire- and grazing-dependent heterogeneity using distance estimates from line transect surveys and program Distance 6.0 to calculate species-specific detection probabilities and densities (Thomas et al. 2010). We then used density estimates to create general linear models for each of the five most abundant obligate-breeding grassland bird species (sensu Vickery et al. 1999). We ran two linear models for each of the five species to assess the influence of the number of patches (i.e., level of heterogeneity) and the effect of fire return interval on individual species abundances. We realize that fire return interval and the number of patches are highly correlated (i.e., greater fire return intervals in this study will increase the number of patches), but to make our results most applicable to future conservation, separate analysis on the number of patches (heterogeneity) and fire return interval makes our results more interpretable.

Finally, we used transect-level vegetation data to examine the influence of finer-scale vegetation structure and composition that result from disturbance processes on individual species abundances. To do this, we used univariate general linear models that could explain relationships between individual species abundances and vegetation parameters that were measured at breeding bird transects. We used transect-level vegetation parameters and species abundances because using 


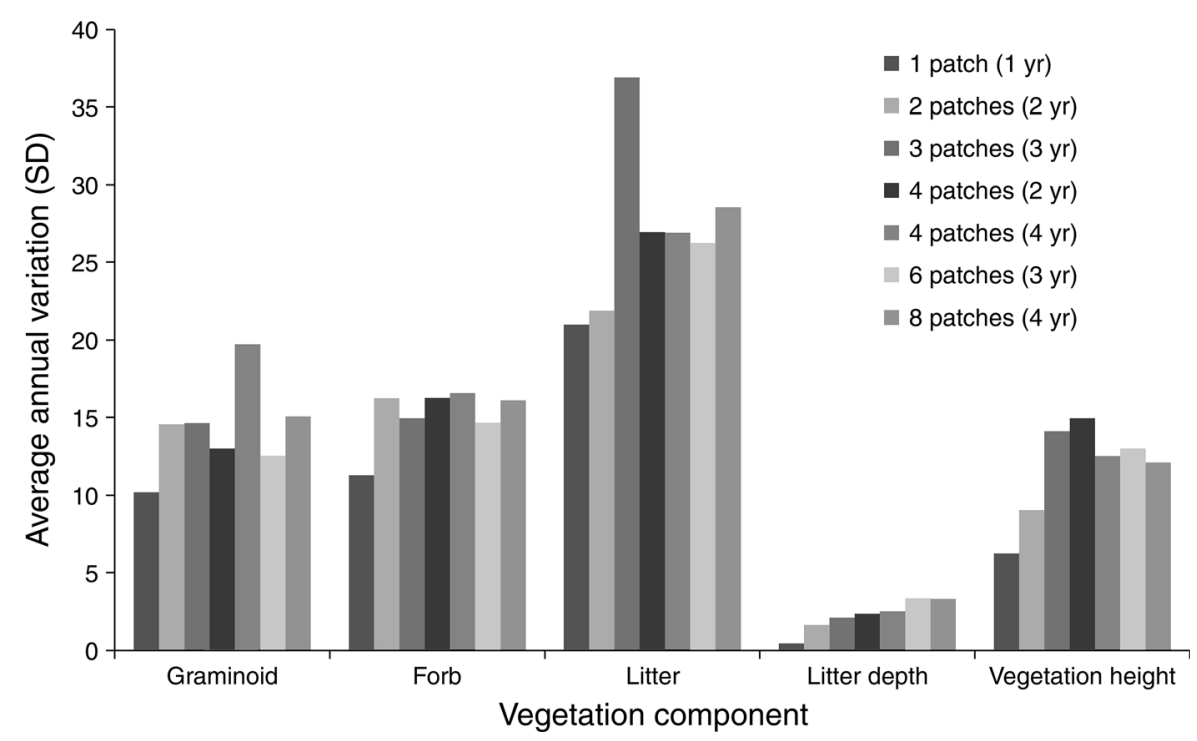

FIG. 2. Vegetation heterogeneity shown as standard deviation of vegetation components measured along each breeding bird transect in experimental landscapes ranging from one to eight patches at the Tallgrass Prairie Preserve, Oklahoma, USA.

landscape-level means would average away the variation within landscapes that is probably responsible for species selection of specific vegetation structure and composition resulting from variable timing of fire and grazing processes at the transect scale. We ran a series of eight models for all five species of interest. After calculating Pearson correlation coefficients for vegetation components and removing those with values $>$ 0.60 , we only present the outcomes of models for the five uncorrelated vegetation parameters.

\section{RESULTS}

We detected 5534 individuals of 35 different bird species (see Appendix). Of the species detected, 12 were obligate grassland breeding birds, 10 were facultative grassland breeding birds, and 13 were species associated with shrubland, forest, or wetland. However, the grassland bird community was dominated by five species that made up nearly $94 \%$ of all detections. The most frequently encountered species were Dickcissel (Spiza americana), Grasshopper Sparrow (Ammodramus savannarum; see Plate 1), Eastern Meadowlark (Sturnella Magna), Henslow's Sparrow (Ammodramus henslowii), and Upland Sandpiper (Bartramia longicauda). No other species accounted for $\geq 1 \%$ of the total detections. Therefore, all of our analyses focused on the five most abundant grassland breeding birds that have the greatest potential of being affected by varying levels of fire- and grazing-dependent heterogeneity.

Analysis of our seven experimental landscapes demonstrated that the grassland bird community is strongly dependent on heterogeneity. Grassland heterogeneity, quantified as the variation in vegetation components, generally increased at the landscape scale with an increase in the number of patches within experimental landscapes
(Fig. 2). As a result, we found a significant, positive linear relationship between landscape-level spatial heterogeneity and grassland bird community diversity (Fig. 3).

Our examination of the bird community using DCA explained $>87 \%$ of the variation in the grassland breeding bird community at the landscape level (Fig. 4A). Moreover, modeling of bird community stability showed a significant, negative relationship between community change index and the number of patches in an experimental landscape (Fig. 4B), indicating that increased heterogeneity at landscape scales resulted in more stable bird communities over time. In fact, the most homogenous experimental landscape experienced nearly four times greater change in the grassland bird community than the most heterogeneous experimental landscape across the three years of the study.

At finer, transect scales we found that greater heterogeneity resulted in increased bird community

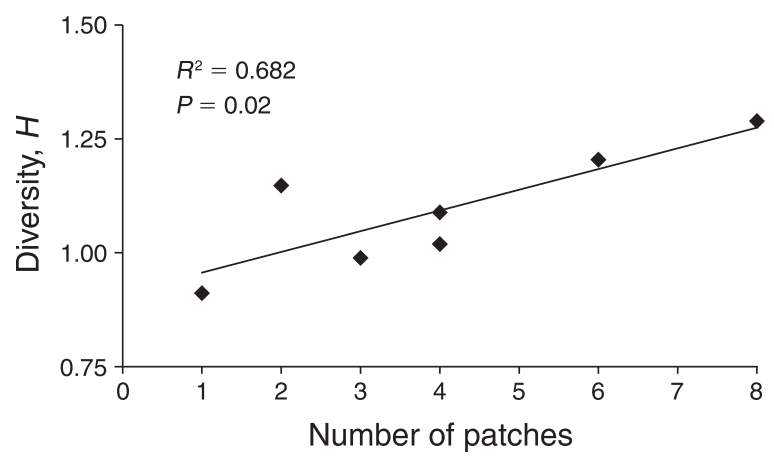

FIG. 3. Grassland bird community diversity represented as Shannon's diversity index in response to fire- and grazingdependent heterogeneity across seven experimental landscapes at the Tallgrass Prairie Preserve. An increasing number of patches represents increasing heterogeneity. 

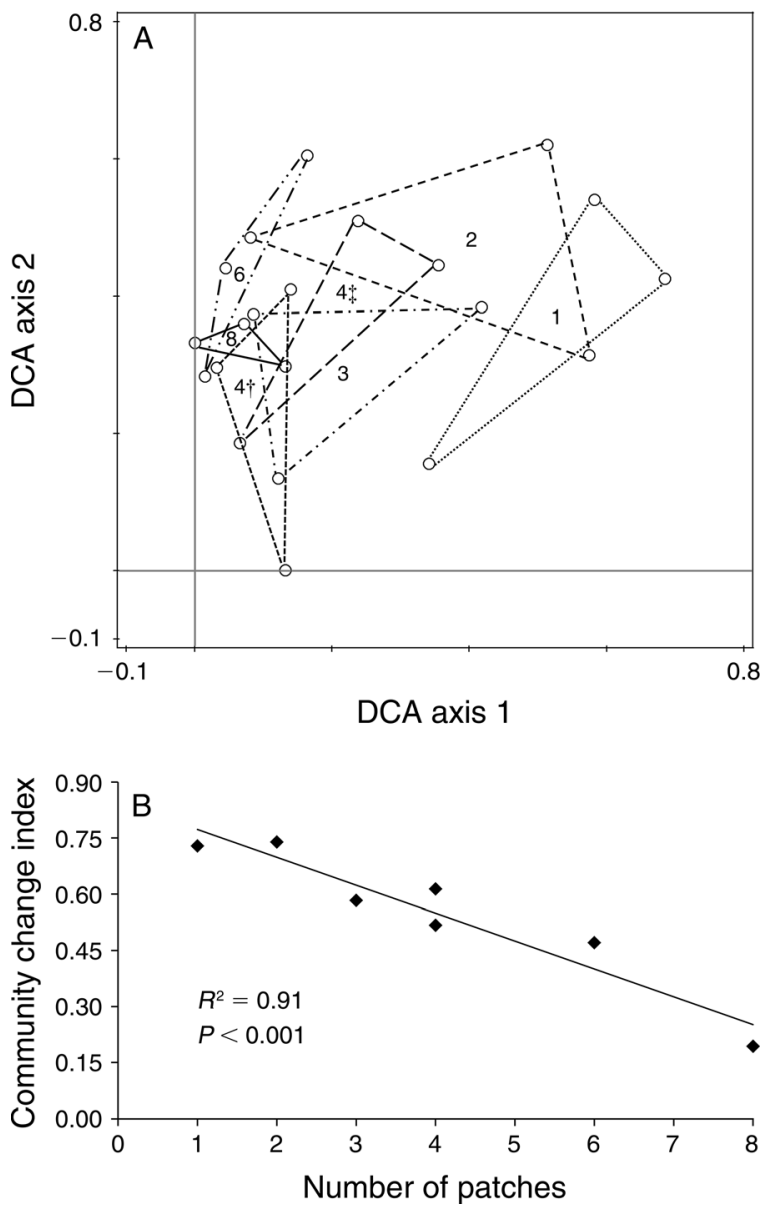

FIG. 4. (A) Biplot of detrended correspondence analysis (DCA) showing axis 1 and axis 2 loadings of site scores representing bird community dissimilarity across a gradient of fire- and grazing-dependent heterogeneity at the Tallgrass Prairie Preserve. Polygons were formed by connecting the site scores for each experimental landscape for all three years of the study. Numbers in the center of polygons represent the number of patches resulting from pyric herbivory. The $\uparrow$ symbol denotes an experimental landscape with four-year fire return interval and spring-only fire; the $\$$ symbol denotes an experimental landscape with two-year fire return interval and spring and summer fires. (B) Sum of the range of detrended correspondence analysis axis 1 and axis 2 site scores (i.e., community change index) as a function of fire- and grazing-dependent heterogeneity. A strong, negative relationship between the community change index and heterogeneity signifies less change in the avian community at landscape scales when more heterogeneity is present.

variability within experimental landscapes over time (Fig. 5). In other words, experimental landscapes with the greatest number of patches had transects with greater variation in the bird community over time. Transects in the experimental landscapes with the greatest number of patches had a variation index of $0.48 \pm 0.10$ (mean $\pm \mathrm{SE}$ ) across the three years, whereas transects in the experimental landscapes with the fewest patches only had a variation index of $0.15 \pm 0.01$. This result is reflected in the variation of vegetation parameters at a landscape level: experimental landscapes with few patches have little variability (i.e., range in standard deviation) in vegetation components, whereas experimental landscapes with many patches have the most variable vegetation as a result of out-of-sequence successional recovery (Fig. 2).

The strength of individual species' responses to heterogeneity varied, but four of the five focal species showed statistically significant or near-significant increases in abundance as a result of increased heterogeneity at broad, landscape-level scales (Fig. 6). The Dickcissel, a generalist species and the most frequently detected bird in this study, was the only breeding bird examined that did not show a response to fire return interval or the number of patches in an experimental landscape. Three of the five species examined had a significant, positive relationship with heterogeneity, and variation in Henslow's Sparrow abundance was best explained by fire return interval (Fig. 6).

Within experimental landscapes at the transect scale, we found that litter cover, litter depth, and vegetation height were significant in explaining breeding bird abundances for most species (Table 1). Dickcissel, Henslow's Sparrow, and Eastern Meadowlark all showed positive relationships with litter depth or litter cover within patches, whereas Grasshopper Sparrow abundance decreased with increasing litter depth, and Upland Sandpiper abundance was most explained by a negative association with vegetation height (Table 1).

\section{DISCUSSION}

Restoring heterogeneity to dynamic grassland ecosystems can benefit biodiversity (Collins 2000, Fuhlendorf et al. 2006, Coppedge et al. 2008, Hovick et al. 2014). The amount of heterogeneity and the influence on the stability of communities, however, have received much less investigation, especially on upper trophic levels at landscape scales. Our examination of seven experimental landscapes representing a gradient of fire- and grazing-

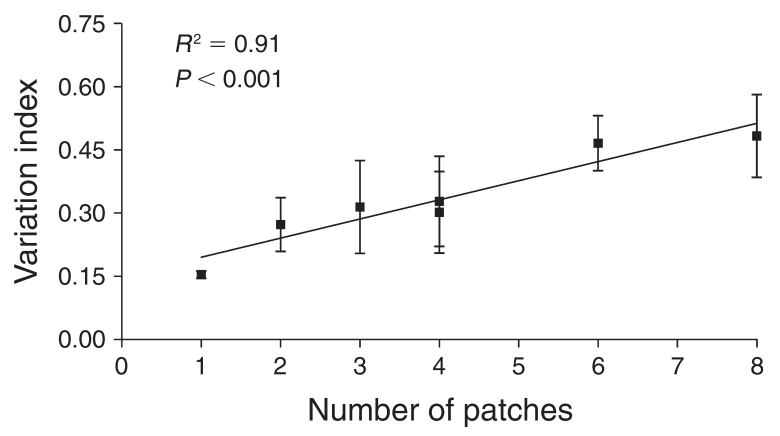

FIG. 5. The standard deviation of detrended correspondence analysis axis 1 scores (i.e., variation index) at the transect scale within experimental landscapes, showing grassland bird community variation as a function of heterogeneity at the Tallgrass Prairie Preserve. Bird community variation at the transect scale within experimental landscapes increased with increasing heterogeneity. Error bars show SE. 


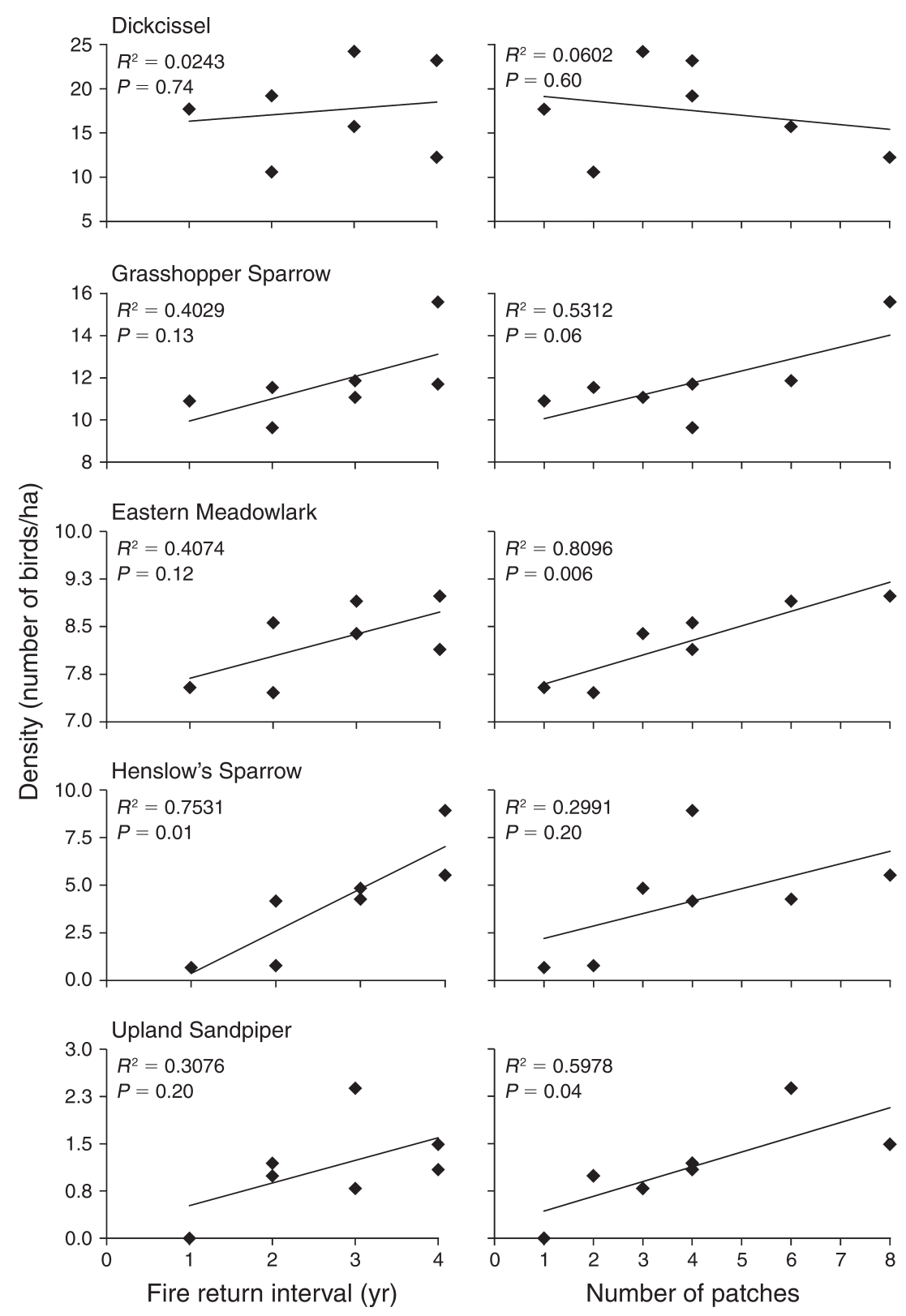

FIG. 6. The responses of individual species to fire return intervals and the number of patches within an experimental landscape at the Tallgrass Prairie Preserve, Oklahoma, USA.

dependent heterogeneity demonstrated that bird diversity and abundance are strongly associated with increased heterogeneity; nearly all species reached maximum abundances in the most heterogeneous landscapes and diversity was positively associated with heterogeneity. Furthermore, heterogeneity increased bird community stability at landscape scales. Many studies have reported a positive relationship between diversity and community stability (Tilman 1996, Brown 2003, Ives and Carpenter 2007, Jiang and $\mathrm{Pu} \mathrm{2009,}$ Downing et al. 2014), but this study provides a unique example of applied research influencing community stability at upper trophic levels at scales relevant to management. These results give new evidence supporting the role of heterogeneity in the conservation of biodiversity and community stability in rangeland systems and substantiate the claims that spatial and temporal heterogeneity and complexity are critical elements in ecosystem function (Christensen 1997). Additionally, our results provide direct application to management because of our landscape-scale real-world experimental design, and they stress the importance of variable disturbance patterns to improve conservation of breeding grassland birds (see Plate 1). Because we report avian densities and abundances, it is worth noting that density can be a misleading indicator of habitat quality 
TABLE 1. Results of univariate regression showing the influence of vegetation components on grassland bird abundance at the transect scale within experimental landscapes managed with pyric herbivory at the Tallgrass Prairie Preserve, Oklahoma, USA, 2011-2013.

\begin{tabular}{|c|c|c|c|c|c|c|c|c|c|c|}
\hline \multirow{2}{*}{$\begin{array}{l}\text { Vegetation } \\
\text { component }\end{array}$} & \multicolumn{2}{|c|}{ Dickcissel } & \multicolumn{2}{|c|}{$\begin{array}{l}\text { Grasshopper } \\
\text { Sparrow }\end{array}$} & \multicolumn{2}{|c|}{$\begin{array}{c}\text { Eastern } \\
\text { Meadowlark }\end{array}$} & \multicolumn{2}{|c|}{$\begin{array}{l}\text { Henslow's } \\
\text { Sparrow }\end{array}$} & \multicolumn{2}{|c|}{$\begin{array}{c}\text { Upland } \\
\text { Sandpiper }\end{array}$} \\
\hline & $\beta$ & $r^{2}$ & $\beta$ & $r^{2}$ & $\beta$ & $r^{2}$ & $\beta$ & $r^{2}$ & $\beta$ & $r^{2}$ \\
\hline Grass cover & 0.05 & 0.02 & -0.001 & $<0.001$ & 0.02 & $0.02 *$ & 0.06 & $0.14 *$ & -0.008 & $0.02 *$ \\
\hline Forb cover & 0.10 & $0.08 *$ & -0.003 & $<0.001$ & -0.001 & $<0.001$ & -0.02 & $0.02 *$ & -0.003 & 0.005 \\
\hline Litter cover & 0.05 & $0.08 *$ & $<0.001$ & $<0.001$ & 0.02 & $0.06^{*}$ & 0.04 & $0.30^{*}$ & -0.005 & $0.05^{*}$ \\
\hline Litter depth & 0.49 & $0.06 *$ & -0.18 & $0.04 *$ & 0.02 & $<0.001$ & 0.51 & $0.40 *$ & -0.05 & $0.04 *$ \\
\hline Veg. height & 0.23 & $0.27 *$ & -0.02 & 0.009 & 0.02 & $0.02 *$ & 0.08 & $0.22 *$ & -0.02 & $0.13^{*}$ \\
\hline
\end{tabular}

Notes: Univariate results indicate that most species are significantly impacted by litter accumulation and vegetation (Veg.) height, two components that are greatly influenced by fire and grazing processes within landscapes and moderated across experimental landscapes with greater heterogeneity. The regression coefficient $\beta$ is the estimate.

$* P \leq 0.05$

and therefore the implications for avian conservation should be interpreted with some caution (Van Horne 1983). However, in a review of bird counts as environmental indicators, higher densities resulted in higher recruitment per capita and per unit of land area $72 \%$ and $85 \%$ of the time, respectively (Bock and Jones 2004).

We found that fire- and grazing-dependent heterogeneity increased variability in vegetation cover and structure at landscape scales. Differential timing of disturbance across the landscape creates a corresponding out-of-phase succession in vegetation within experimental landscapes, which in turn is responsible for greater heterogeneity at broad spatial scales and increased temporal heterogeneity at fine spatial scales (Fuhlendorf et al. 2006, Derner et al. 2009). This spatial heterogeneity of vegetation structure provides greater breadth of suitable nesting locations for grassland bird species and increases the variety of grassland bird communities that can occur across the landscape (Fuhlendorf et al. 2006, Gregory et al. 2010, Little et al. 2012). Although there is not a clear link to a mechanistic feedback between heterogeneity and birds as there is for plants, it is clear that dynamic grasslands that embrace the shifting grassland mosaic can reduce the sensitivity to annual changes in the avian community brought on by attempts to reduce dynamism in grasslands through annual burning and grazing. Moreover, maximizing variation in vegetation structure can buffer against environmental shocks or threats associated with predation and resource shortages (Brown 2003, Ives and Carpenter 2007). As a result, we found that experimental landscapes with greater heterogeneity had less community change, whereas those with more homogeneous structure experienced nearly four times more community change. This finding supports previous recommendations to increase the diversity of management practices used in the North American grasslands to overcome the current state of homogeneity and improve grassland bird conservation (Powell 2008, Rahmig et al. 2009).

Increased temporal stability in the avian community with increased landscape-level heterogeneity may be explained through multiple mechanisms, including increased resources and refugia, and could be the result of a phenomenon commonly referred to as the portfolio effect: as the community diversifies, constancy increases over time (Doak et al. 1998, Tilman et al. 1998). Analogous to advice given by a financial consultant, the portfolio effect refers to increasing diversity so that the aggregate value (e.g., diversity, biomass) will be less variable through time. In this case, fire- and grazingdependent heterogeneity at broad scales created suitable environments that elevated species richness in the most heterogeneous experimental landscapes, thereby creating a temporally stable avian community because of the complementary or independent dynamics among species that perform similar ecosystem functions (Schindler et al. 2010).

Because heterogeneity is largely associated with spatial and temporal variability, it is highly dependent on scale and should be evaluated across several scales (Fuhlendorf and Smeins 1999). To address this, we examined community dynamics at the transect scale in addition to landscape scales. We found a strong positive association with transect-level variation in species abundance and the number of patches in an experimental landscape. In other words, at fine scales, heterogeneity increased temporal variability in the grassland bird community, but at broad spatial scales, heterogeneity resulted in greater temporal stability. This fine-scale variation over time occurs as some specialized species select areas of low-stature grazing lawns in recently burned patches (i.e., Upland Sandpiper), whereas other species primarily select tall, unburned patches that occur through time as patches succeed following disturbance (i.e., Henslow's Sparrow). As a result, within experimental landscapes, diversity is high over time but low at the transect scale in a given breeding season. This temporal heterogeneity within patches demonstrates the dependence of grassland birds on disturbance and illustrates the variation in species composition as succession takes place over time (Skowno and Bond 2003).

Within-landscape selection was best explained by finescale habitat associations at the transect scale, which illustrated that litter cover, litter depth, and vegetation 


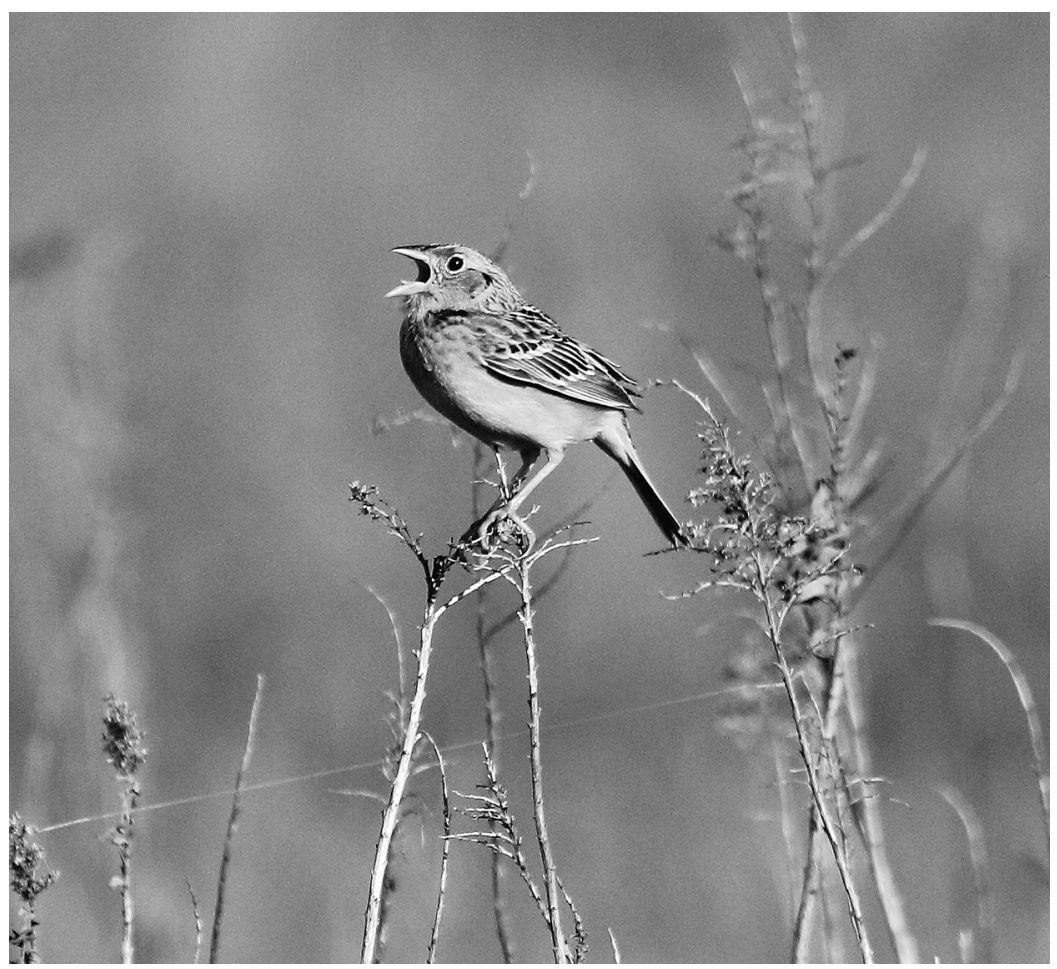

Plate 1. Singing adult male Grasshopper Sparrow in an experimental landscape managed for heterogeneity at The Nature Conservancy's Tallgrass Prairie Preserve, Osage County, Oklahoma, USA. Photo credit: T. J. Hovick.

height were the most influential parameters affecting individual species abundances. Grassland birds select nesting habitats with very specific characteristics, which suggests that they evolved in grassland environments with highly variable disturbance regimes that created structurally diverse habitats (Cody 1985, Knopf 1996). Despite the specific affinities of each species for certain vegetation structure, no species reached maximum abundances in an experimental landscape with limited heterogeneity. This suggests that patches within the most heterogeneous experimental landscape create optimal nesting conditions, or that species may inherently select for more diverse landscapes because they can provide stabilization of resources and increased refugia from potential environmental stressors (Brown 2007).

The grassland bird community of the southern Great Plains is made up of a relatively low number of species and is dominated by a few very abundant species; as a result, our analysis was focused on the five most abundant grassland breeding species. Therefore, while we do speculate that heterogeneity plays an important role in all habitat types, our results only directly apply to grassland breeding birds. Our research area represents the southern extent of tallgrass prairie and this may explain the lack of overall diversity in the grassland bird community and the abundance of a limited number of species. Moreover, this area experiences a wide range of climatic conditions and species must be able to cope with great annual variation in rainfall and temperature. In part, heterogeneity can play an important role in buffering against this variation. For example, annually burned patches may have highly variable amounts of production, depending upon rainfall and early-spring temperatures, whereas landscapes with a variety of patches with different fire return intervals will have a structural mosaic regardless of interannual variation in climatic conditions. As previous work has demonstrated, heterogeneity can act as a buffer against climatic variation for cattle production (Allred et al. 2014), and our results demonstrate that this buffering effect applies to the stability of the grassland bird community as well.

Maintaining and restoring spatiotemporally variable disturbances that produce heterogeneity in herbaceous systems has increased diversity in multiple taxa (Fuhlendorf et al. 2006, 2010, Engle et al. 2008), and has frequently been suggested as the best method to promote the conservation of grassland bird communities (Askins 2000, Walk and Warner 2000, Powell 2006). This study now provides an approach that allows conservationists and land managers to understand how specific disturbance regimes can maximize individual species abundances, and perhaps more importantly, this research illustrates the significance of heterogeneity at broad scales to optimize avian diversity and stability. Additionally, our findings suggest that grassland bird diversity in the southern Great Plains is maximized with a three- to four-year fire return interval, which supports tree ring data indicating that this region had a mean fire 
return interval for the early part of the 20th century of 3.76 years (Allen and Palmer 2011). It is more challenging to relate our burn patch sizes to historic records, but it is safe to assume that most historic fires were very large in context and typically were regulated by natural fire breaks. As a result, we recommend that large patch sizes be used by land managers and ranchers when possible and that they burn no more than onethird of the landscape annually. Furthermore, our results add to a growing body of work supporting the role of diversity in community stability and ecosystem function and imply that managing for heterogeneity may have other positive benefits to conservation that we have yet to quantify (Brown 2003, Loreau et al. 2003, Isbell et al. 2009, Downing et al. 2014).

\section{ACKNOWLEDGMENTS}

We thank Joseph Lautenbach, Karlee Buckles, and Kyle Meadows for their assistance with data collection. We also thank The Nature Conservancy for providing housing and maintaining this complex experimental design at the Tallgrass Prairie Preserve. Finally, we acknowledge Devan McGranahan for comments on an earlier version of this paper. This work was supported by funding from USDA-AFRI Managed Ecosystems grant \#2010-85101-20457 and by the Oklahoma Agricultural Experiment Station.

\section{Literature Cited}

Allen, M. S., and M. W. Palmer. 2011. Fire history of a prairie/ forest boundary: more than 250 years of frequent fire in a North American tallgrass prairie. Journal of Vegetation Science 22:436-444.

Allred, B. W., S. D. Fuhlendorf, D. M. Engle, and R. D. Elmore. 2011. Ungulate preference for burned patches reveals the strength of fire-grazing interaction. Ecology and Evolution 1:132-144.

Allred, B. W., J. D. Scasta, T. J. Hovick, S. D. Fuhlendorf, and R. G. Hamilton. 2014. Spatial heterogeneity stabilizes livestock productivity in a changing climate. Agriculture, Ecosystems and Environment 193:37-41.

Anderson, R. C. 2006. Evolution and origin of the Central Grassland of North America: climate, fire, and mammalian grazers. Journal of the Torrey Botanical Society 133:626647.

Askins, R. A. 2000. Restoring North America's birds: Lessons from landscape ecology. Yale University Press, New Haven, Connecticut, USA.

Augustine, D. J., and J. D. Derner. 2013. Controls over the strength and timing of the fire-grazer interactions in a semiarid rangeland. Journal of Applied Ecology 51:242-250.

Benton, T. G., J. A. Vickery, and J. D. Wilson. 2003. Farmland biodiversity: is habitat heterogeneity the key? Trends in Ecology and Evolution 18:182-188.

Bock, C. E., and Z. F. Jones. 2004. Avian habitat evaluation: Should counting birds count? Frontiers in Ecology and the Environment 2:403-410.

Brown, B. L. 2003. Spatial heterogeneity reduces temporal variability in stream insect communities. Ecology Letters 6:316-325.

Brown, B. L. 2007. Habitat heterogeneity and disturbance influence patterns of community temporal variability in a small temperate stream. Hydrobiologia 586:93-106.

Buckland, S. T. 2001. Introduction to distance sampling: estimating abundance of biological populations. Oxford University Press, Oxford, UK.

Cardinale, B. J., et al. 2012. Biodiversity loss and its impact on humanity. Nature 486:59-68.
Carey, A. B. 2003. Biocomplexity and restoration of biodiversity in temperate coniferous forest: inducing spatial heterogeneity with variable-density thinning. Forestry 76:127-136.

Christensen, N. L. 1997. Managing for heterogeneity and complexity on dynamic landscapes. Pages $167-186$ in S. T. A. Pickett, R. S. Otsfeld, M. Shachak, and G. E. Likens, editors. The ecological basis for conservation: heterogeneity, ecosystems, and biodiversity. Chapman and Hall, New York, New York, USA.

Cody, M. L. 1985. Habitat selection in grassland and opencountry birds. Pages 191-226 in M. L. Cody, editor. Habitat selection in birds. Academic Press, Orlando, Florida, USA.

Collins, S. L. 2000. Disturbance frequency and community stability in native tallgrass prairie. American Naturalist 155:311-325.

Coppedge, B. R., S. D. Fuhlendorf, W. C. Harrell, and D. M. Engle. 2008. Avian community response to vegetation and structural features in grasslands managed with fire and grazing. Biological Conservation 141:1196-1203.

Derner, J., W. K. Lauenroth, P. Stapp, and D. J. Augustine. 2009. Livestock as ecosystem engineers for grassland bird habitat in the Western Great Plains of North America. Rangeland Ecology and Management 62:111-118.

Doak, D. F., D. Bigger, E. K. Harding, M. A. Marvier, R. E. O'Malley, and D. Thomson. 1998. The statistical inevitability of stability-diversity relationships in community ecology. American Naturalist 151:264-276.

Downing, A. L., B. L. Brown, and M. A. Leibold. 2014. Multiple diversity-stability mechanisms enhance population and community stability in aquatic food webs. Ecology 95:173-184.

Engle, D. M., S. D. Fuhlendorf, A. Roper, and D. M. Leslie, Jr. 2008. Invertebrate community response to a shifting mosaic of habitat. Rangeland Ecology and Management 64:394403.

Fahrig, L., J. Baudry, L. Brotons, F. G. Burel, T. O. Crist, R. J. Fuller, C. Srami, G. M. Siriwardena, and J.-L. Martin. 2011. Functional landscape heterogeneity and animal biodiversity in agricultural landscapes. Ecology Letters 14:101-112.

Foster, D., F. Swanson, J. Aber, I. Burke, N. Brokaw, D. Tilman, and A. Knapp. 2003. The importance of land-use legacies to ecology and conservation. BioScience 53:77-88.

Fuhlendorf, S. D., and D. E. Engle. 2001. Restoring heterogeneity on rangelands: ecosystem management based on evolutionary grazing patterns. BioScience 51:625-632.

Fuhlendorf, S. D., and D. M. Engle. 2004. Application of the fire-grazing interaction to restore a shifting mosaic on tallgrass prairie. Journal of Applied Ecology 41:604-614.

Fuhlendorf, S. D., D. M. Engle, R. D. Elmore, R. F. Limb, and T. G. Bidwell. 2012. Conservation of pattern and process: developing an alternative paradigm of rangeland management. Rangeland Ecology and Management 65:579-589.

Fuhlendorf, S. D., D. M. Engle, J. Kerby, and R. Hamilton. 2009. Pyric herbivory: re-wilding landscapes through the recoupling of fire and grazing. Conservation Biology 23:588598.

Fuhlendorf, S. D., W. C. Harrell, D. M. Engle, R. G. Hamilton, C. A. Davis, and D. M. Leslie, Jr. 2006. Should heterogeneity be the basis for conservation? Grassland bird response to fire and grazing. Ecological Applications 16:1706-1716.

Fuhlendorf, S. D., and F. E. Smeins. 1999. Scaling effects of grazing in a semi-arid savanna. Journal of Vegetation Science 10:617-628.

Fuhlendorf, S. D., D. E. Townsend II, R. D. Elmore, and D. M. Engle. 2010. Pyric-herbivory to promote rangeland heterogeneity: evidence from small mammal communities. Rangeland Ecology and Management 63:670-678.

Gregory, N. C., R. L. Sensenig, and D. S. Wilcove. 2010. Effects of controlled fire and livestock grazing on bird communities in East Africa savannas. Conservation Biology 24:1606-1616. 
Guthery, F. S., T. A. Doerr, and M. A. Taylor. 1981. Use of a profile board in sand shinnery oak communities. Journal of Rangeland Management 34:157-15.

Hoekstra, J. M., T. M. Boucher, T. H. Ricketts, and C. Roberts. 2005. Confronting a biome crisis: global disparities of habitat loss and protection. Ecology Letters 8:23-29.

Hovick, T. J., R. D. Elmore, and S. D. Fuhlendorf. 2014. Structural heterogeneity increases diversity of non-breeding grassland birds. Ecosphere 5:art62

Isbell, F. I., H. W. Polley, and B. J. Wilsey. 2009. Biodiversity, productivity and the temporal stability of productivity: patterns and processes. Ecology Letters 12:443-451.

Ives, A. R., and S. R. Carpenter. 2007. Stability and diversity of ecosystems. Science 317:58-62.

Jiang, L., and Z. C. Pu. 2009. Different effects of species diversity on temporal stability in single-trophic and multitrophic communities. American Naturalist 174:651-659.

Knopf, F. L. 1996. Prairie legacies-birds. Pages 135-148 in F. B. Samson and F. L. Knopf, editors. Prairie conservation: preserving North America's most endangered ecosystem. Island Press, Washington, D.C., USA.

Little, I. T., P. A. R. Hockey, and R. Jansen. 2012. A burning issue: fire overrides grazing as a disturbance driver for South African grassland bird and arthropod assemblage structure and diversity. Biological Conservation 158:258-270.

Loreau, M., N. Mouquet, and A. Gonzalez. 2003. Biodiversity as spatial insurance in heterogeneous landscapes. Proceedings of the National Academy of Sciences USA 100:12765-12770.

McGranahan, D. A., D. M. Engle, S. D. Fuhlendorf, S. J. Winter, J. R. Miller, and D. M. Debinski. 2012. Spatial heterogeneity across five rangelands managed with pyricherbivory. Journal of Applied Ecology 49:903-910.

Micheli, F., K. L. Cottingham, J. Bascompte, O. N. Bjornstad, G. L. Eckert, J. M. Fischer, T. H. Keitt, B. E. Kendall, J. L. Klug, and J. A. Rusak. 1999. The dual nature of community variability. Oikos 85:161-169.

Naeem, S. 2002. Ecosystem consequences of biodiversity loss: the evolution of a paradigm. Ecology 83:1537-1552.

Naeem, S., and S. Li. 1997. Biodiversity enhances ecosystem reliability. Nature 390:507-509.

Nudds, T. D. 1977. Quantifying the vegetative structure of wildlife cover. Wildlife Society Bulletin 5:113-117.

Palmer, M. A., R. F. Ambrose, and N. L. Poff. 1997. Ecological theory and community restoration ecology. Restoration Ecology 5:291-300.

Pillsbury, F. C., J. R. Miller, D. M. Debinski, and D. M. Engle. 2011. Another tool in the toolbox? Using fire and grazing to promote bird diversity in highly fragmented landscapes. Ecosphere 2:art 28.

Pimm, S. L., G. J. Russell, J. L. Gittleman, and T. M. Brooks. 1995. The future of biodiversity. Science 269:347-350.

Powell, A. F. L. A. 2006. Effects of prescribed burns and bison (Bos bison) grazing on breeding bird abundances in tallgrass prairie. Auk 123:183-197.

Powell, A. F. L. A. 2008. Responses of breeding birds in tallgrass prairie to fire and cattle grazing. Journal of Field Ornithology 79:41-52.
Rahmig, C. J., W. E. Jensen, and K. A. With. 2009. Grassland bird responses to land management in the largest remaining tallgrass prairie. Conservation Biology 23:420-432.

Ralph, C. J. G. R. Geupal, P. Pyle, T. E. Martin, and D. F. DeSante. 1993. Handbook of field methods for monitoring landbirds. PSW-GTR-144. USDA, Forest Service, Pacific Southwest Research Station, Albany, California, USA.

Schindler, D. E., R. Hilborn, B. Chasco, C. P. Boatright, T. P. Quinn, L. A. Rogers, and M. S. Webster. 2010. Population diversity and the portfolio effect in an exploited species. Nature 465:609-313.

Skowno, A. L., and W. J. Bond. 2003. Bird community composition in an actively managed savanna reserve, importance of vegetation structure and vegetation composition. Biodiversity and Conservation 12:2279-2294.

Steinauer, E. M., and S. L. Collins. 1996. Prairie ecology-the tallgrass prairie. Pages 39-52 in F. B. Samson and F. L. Knopf, editors. Prairie conservation: preserving North America's most endangered ecosystem. Island Press, Washington, D.C., USA.

Tartowski, S. L., et al. 1997. Toward a resolution of conflicting paradigms. Pages 187-192 in S. T. A. Pickett, R. S. Otsfeld, M. Shachak, and G. E. Likens, editors. The ecological basis for conservation: heterogeneity, ecosystems, and biodiversity. Chapman and Hall, New York, New York, USA.

ter Braak, C. J. F., and P. Šmilauer. 2012. CANOCO reference manual and user's guide: software for canonical community ordination (version 5.0). Biometris, Wageningen, The Netherlands.

Thomas, L., S. T. Buckland, E. A. Rexstad, J. L. Laake, S. Strindberg, S. L. Hedley, J. R. B. Bishop, T. A. Marques, and K. P. Burnham. 2010. Distance software: Design and analysis of distance sampling surveys for estimating population size. Journal of Applied Ecology 47:5-14.

Tilman, D. 1996. Biodiversity: population versus ecosystem stability. Ecology 77:350-363.

Tilman, D., C. L. Lehman, and C. E. Bristow. 1998. Diversitystability relationships: statistical inevitability or ecological consequence? American Naturalist 151:277-282.

Van Horne, B. 1983. Density as a misleading indicator of habitat quality. Journal of Wildlife Management 47:893-901.

Vickery, P. D., P. L. Tubaro, J. M. Cados Da Silva, B. G. Peterjohn, J. R. Herkert, and R. B. Cavlacanti. 1999. Conservation of grassland birds in the Western Hemisphere. Studies in Avian Biology 19:2-26.

Walk, J. W., and R. E. Warner. 2000. Grassland management of the conservation of songbirds in the Midwestern USA. Biological Conservation 94:165-172.

Wiens, J. A. 1997. The emerging role of patchiness in conservation biology. Pages 167-186 in S. T. A. Pickett, R. S. Otsfeld, M. Shachak, and G. E. Likens, editors. The ecological basis for conservation: heterogeneity, ecosystems, and biodiversity. Chapman and Hall, New York, New York, USA.

Wu, J., and O. L. Loucks. 1995. From balance of nature to hierarchical patch dynamics. Quarterly Review of Biology 70:439-466.

\section{Supplemental Material}

Ecological Archives

The Appendix is available online: http://dx.doi.org/10.1890/14-1067.1.sm 